\title{
Multiple paternity and postcopulatory sexual selection in a hermaphrodite: what influences sperm precedence in the garden snail Helix aspersa?
}

\author{
GUILLAUME EVANNO ${ }^{*}$ LUC MADEC† and JEAN-FRANÇOIS ARNAUD‡ \\ *Département d'Ecologie et Evolution, Bâtiment de Biologie, Université de Lausanne, CH-1015 Lausanne, Switzerland, +UMR CNRS \\ 6553, Université de Rennes 1, Campus de Beaulieu, Avenue du Général, Leclerc, 35042 Rennes cedex, France, łUMR CNRS 8016, \\ Laboratoire de Génétique et Evolution des Populations Végétales, Bât. SN2, Universitéde Lille 1, 59655 Villeneuve d'Ascq cedex, France
}

\begin{abstract}
Sperm competition has been studied in many gonochoric animals but little is known about its occurrence in simultaneous hermaphrodites, especially in land snails. The reproductive behaviour of the land snail Helix aspersa involves several features, like multiple mating, long-term sperm storage and dart-shooting behaviour, which may promote sperm competition. Cryptic female choice may also occur through a spermatheca subdivided into tubules, which potentially allows compartmentalized sperm storage of successive mates. In order to determine the outcome of postcopulatory sexual selection in this species, we designed a cross-breeding experiment where a recipient ('female') mated with two sperm donors ('males'). Mates came from either the same population as the recipient or from a distinct one. To test for the influence a recipient can have on the paternity of its offspring, we excluded the effects of dart shooting by using only virgin snails as sperm donors because they do not shoot any dart before their first copulation. We measured the effects of size of mates as well as time to first and second mating on second mate sperm precedence $\left(P_{2} ;\right.$ established using microsatellite markers). Multiple paternity was detected in $62.5 \%$ of clutches and overall there was first-mate sperm precedence with a mean $P_{2}$ of 0.24 . Generalized linear modelling revealed that the best predictors of paternity were the time between matings and the time before first mating. Overall, both first and second mates that copulated quickly got greater parentage, which may suggest that postcopulatory events influence patterns of sperm precedence in the garden snail.
\end{abstract}

Keywords: cryptic female choice, Helix aspersa, hermaphroditic snail, $P_{2}$, sperm competition

Received 5 September 2004; revision received 12 November 2004; accepted 29 November 2004

Introduction

Sexual selection is the evolutionary process that favours selection for traits associated with mating success and partner choice. Mating success often trades off with survival and sexual selection accounts for many of the attractive ornaments of various plants and animals (Andersson 1994). Sexual selection is generally viewed as a process operating on the diploid stage of the life cycle. However, it has been documented that females of several species actively seek multiple copulation partners, leading to postcopulatory

Correspondence: Guillaume Evanno, Fax: + 412169242 65; Email: guillaume.evanno@unil.ch sexual selection (Birkhead \& Pizzari 2002). Indeed, in species where multiple inseminations occur, there will be competition among the sperm provided by different fathers. By definition, sperm competition is the competition between the sperm of different males to fertilize the ova of a female (Parker 1970). Females, on their part can potentially choose sperm from different donors if for instance the sperm carry information on male quality. Such a cryptic female choice designates the influence a female can have on fertilization of her eggs after intromission or sperm transfer. This choice is exercised through molecular and physiological mechanisms and/or morphological structures in the female reproductive tract (Eberhard 1996). Overall, recent studies suggest that relative reproductive rates of 
males and females, sperm competition, and quality variation among mates affect the strength of sexual selection (Birkhead \& Pizzari 2002).

Simultaneous hermaphrodites can also experience sexual selection (Charnov 1979; Michiels 1998). However, postcopulatory sexual selection has been rarely investigated in these organisms: multiple mating appears widespread but evidence of mate choice is rare and usually consists of assortative mating. In the particular case of studied helicid land snails that mate multiply (for instance three times per year for Helix aspersa, Fearnley 1993), mating seems generally random with respect to size and relatedness (Baur 1992; Baur \& Baur 1997). This may be because (i) characters involved in mate choice are difficult to detect, or (ii) sexual selection acts essentially during or after copulation. Nonetheless, the long-term sperm-storage ability characteristic of land snails (Murray 1964; Duncan 1975) may increase the potential for postcopulatory sexual selection. The dart-shooting behaviour exhibited by some helicid species, including the land snail $H$. aspersa (Gastropoda: Helicidae), may also promote some forms of postcopulatory sexual selection (Koene \& Chase 1998). Just before copulation, snails attempt to push a calcareous dart into their partners, which eventually enhances the number of sperm stored by the recipient through a temporary modification of its female genitalia caused by chemicals in the mucus covering the dart (Koene \& Chase 1998; Rogers \& Chase 2001, 2002). The donor thus avoids the digestion of most of its sperm in the bursa copulatrix (sperm-digesting organ) of the recipient, and therefore increases its reproductive success (Landolfa et al. 2001).

Land snails are also especially suitable organisms to test for postcopulatory sexual selection because cryptic female choice could occur owing to the presence of a spermatheca subdivided into several tubules, which possibly allow for separate storage of sperm from successive mates (Haase \& Baur 1995; Baminger \& Haase 1999). The ability to exercise cryptic female choice theoretically increases with the number of sperm stores (Hellriegel \& Ward 1998), therefore this phenomenon is potentially important in $H$. aspersa whose spermatheca can have up to 13 tubules (mean $\pm \mathrm{SD}=7.2 \pm$ 2.4; G. Evanno and L. Madec, unpublished). In this species, cryptic female choice might be based on (i) size of mate, larger individuals displaying heritable differences in several fitness related traits, e.g. size and number of progeny (Madec et al. 1998, 2000); or (ii) relatedness, because land snails exhibit poor dispersal capacities so that maximizing paternity of migrant individuals establishing in a preexisting colony may counteract deleterious effects of inbreeding in local populations (see Fearnley 1993; Arnaud \& Laval 2004).

In this study, we investigated the effects of postcopulatory sexual selection on the patterns of siring success in
H. aspersa. To address this issue, a cross-breeding experiment was designed with the following scheme: a group of recipients from one population successively mates with two sperm donors either belonging to the same population as the recipient or to a different one. The resulting pattern of sperm precedence could highlight a higher siring success of allopatric or sympatric mates (Chapman et al. 2003). If partial premating isolation occurs, sympatric mates should outcompete allopatric ones. To avoid this effect, we sampled snails from northwestern Europe because $H$. aspersa populations do not display any incompatibility because of marked differences in distal genitalia in this geographical area (Madec \& Guiller 1994). According to the theory of sexual conflict, allopatric mates may sire more offspring because local snails would be supposed to have only evolved resistance to sympatric mates (Leonard 1992; Rice \& Holland 1997; Parker \& Partridge 1998; Landolfa 2002). The limited dispersal capabilities of snails often lead to a strong population isolation that can result in matings between relatives (Arnaud et al. 1999, 2001). Such matings by proximity are likely to increase inbreeding and its potential deleterious effects (Chen 1993). Consequently, from a female perspective, favouring migrant individuals should be advantageous.

In $H$. aspersa, potential mechanisms involved in postcopulatory sexual selection include dart-shooting behaviour, sperm digestion ability and/or cryptic female choice. The role of dart-shooting behaviour has been widely investigated and many studies have shown its influence in postcopulatory sexual selection (Koene \& Chase 1998; Landolfa et al. 2001; Rogers \& Chase 2001, 2002). However, little is known about the influence of a recipient on the paternity of its offspring through allosperm digestion and cryptic female choice. For this reason, we focused on the female perspective and excluded the effects of dart-shooting behaviour by using only virgin snails that are unable to shoot darts before their first copulation.

\section{Materials and methods}

\section{Study populations and their maintenance}

Three French populations were sampled for mating trials: one group of recipients ('females') and two others used only as sperm donors ('males') in the mating experiments. All sampled snails were immature (less than 1 year) and thus virgin prior to mating experiments. Therefore, dartshooting effects were excluded because virgin snails do not shoot darts during courtship prior to their first copulation (Chung 1986).

Recipients were collected in a snail farm from Rennes (northwestern France) to ensure a sufficient number of immature virgin snails from the same population. The snail farm population originates from a wild population from 
Plouay, $105 \mathrm{~km}$ away from Rennes. One male group was collected in Saint-Sulpice La Forêt (120 km away from Plouay), the second one was sampled in Lille (about $500 \mathrm{~km}$ away from both other localities). We can reasonably assume that no recent gene exchanges occurred between these three populations because Helix aspersa has poor dispersal capabilities which result in striking spatial patterns of genetic variation, even at microgeographical scales of investigations (see Arnaud et al. 1999, 2001). After sampling in March 2001, young snails were kept isolated in plastic boxes the bottoms of which were covered with wet rubber, and the snails were fed ad libitum with composite snail food. In experimental rooms, the photoperiod was set to a $16: 8$ light/dark cycle with a temperature of $20^{\circ} \mathrm{C}$. Snails were reared in these conditions until maturity, which was detected by the formation of a thickening and recurving lip at the edge of shell aperture.

\section{Mating experiments}

Adult recipients mated successively with two individuals from either (i) the same population (called F), (ii) Lille (L), or (iii) Saint-Sulpice (S) (Table 1). Seven mating sequences were tested: LS, SL, FL, LF, FS, SF and FF (control) but we ignored LL and SS because they would not have provided more information related to the questions we addressed in the present study. Mating pairs were kept isolated and we checked twice a night whether copulation occurred. In $H$. aspersa, copulation is always initiated during the night and it lasts at least $6 \mathrm{~h}$ according to Adamo \& Chase (1988). Therefore, to ensure that we would not miss any copulation, the first checking occurred $2 \mathrm{~h}$ after the beginning of the dark period, and the second started $30 \mathrm{~min}$ before the end of this period (i.e. snails were left unobserved about $5.5 \mathrm{~h}$ ).

After the end of their first mating, recipients were placed with a second mate whereas the first one was removed. For the second mating, we checked for the occurrence of copu- lations in the same way as for the first one. All donors were used for only one mating. Two pairs were excluded from analyses because after the copulation, a spermatophore was found in their boxes. Recipients that mated twice were then isolated with a laying jar in their box. Snails were observed daily during 3.5 months during which recipients were allowed to mate only twice and then to lay eggs. We measured the effect of mating sequence on the fecundity (number and mean weight of eggs) of recipients but failed to find any significant relationship (data not shown). The other traits we measured were the body size of mates (measured as the shell's largest diameter to the nearest $0.1 \mathrm{~mm}$ using a vernier calliper), and also temporal variables as time before first mating, time before second mating and time between last copulation and oviposition.

\section{Paternity analysis}

After 1 week of incubation, a sample of 20 eggs (mean clutch size \pm SE $135 \pm 7.9$ ) was randomly taken in first clutches of twice-mated recipients. The proportion of progeny sired by the second mate $\left(P_{2}\right)$ was estimated using three highly polymorphic microsatellite markers ( $\mathrm{Ha} 5, \mathrm{Ha10}$, and $\mathrm{Ha11}$; Guiller et al. 2000). After freezing, eggs were manually crushed and DNA isolated using a classic Chelex resin procedure (Estoup et al. 1996). Polymerase chain reaction (PCR) amplifications were performed in 'Ready to Go' reaction tubes (Amersham-Pharmacia) in a total volume of $25 \mu \mathrm{L}$ including $1.5 \mu \mathrm{L}$ of DNA template. The temperature profile used was: $5 \mathrm{~min}$ at $95^{\circ} \mathrm{C}$ followed by 30 cycles at $94{ }^{\circ} \mathrm{C}$ for $30 \mathrm{~s}, 30 \mathrm{~s}$ at $54{ }^{\circ} \mathrm{C}, 30 \mathrm{~s}$ at $72{ }^{\circ} \mathrm{C}$ and a final cycle at $72{ }^{\circ} \mathrm{C}$ for $5 \mathrm{~min}$. PCR products were analysed using an ABI Prism 310 Genetic Analyser (PE Applied Biosystems) and microsatellite DNA fragment lengths were determined with GENESCAN version 3.1 (PE Applied Biosystems). Parents were similarly typed except genomic DNA was extracted from a foot sample. All genotypes were scored by two

Table 1 Results of mating experiments in terms of once and twice mated recipients, number of clutches obtained, number of clutches whose paternity was determined (see text), times before first and second mating (days), and proportion of progeny sired by the second mate $\left(P_{2}\right)$

\begin{tabular}{|c|c|c|c|c|c|c|c|c|c|}
\hline Mating sequences & LS & SL & FL & $\mathrm{LF}$ & FS & SF & FF & total & mean (SE) \\
\hline Once mated recipients & 9 & 12 & 14 & 10 & 11 & 10 & 12 & 78 & - \\
\hline Twice mated recipients & 7 & 9 & 8 & 10 & 9 & 10 & 12 & 65 & - \\
\hline Clutches & 7 & 6 & 2 & 6 & 3 & 7 & 5 & 36 & - \\
\hline Clutches analysed & 7 & 6 & 2 & 5 & 2 & 6 & 4 & 32 & - \\
\hline Mean time before 1st mating (SE) & $\begin{array}{l}9.4 \\
(3.28)\end{array}$ & $\begin{array}{l}20 \\
(6.90)\end{array}$ & $\begin{array}{l}8.5 \\
(1.49)\end{array}$ & $\begin{array}{c}5.4 \\
(2.04)\end{array}$ & $\begin{array}{l}7 \\
(5.00)\end{array}$ & $\begin{array}{l}13.5 \\
(6.69)\end{array}$ & $\begin{array}{l}8 \\
(5.15)\end{array}$ & - & $\begin{array}{l}11.2 \\
(2.12)\end{array}$ \\
\hline Mean time before 2nd mating (SE) & $\begin{array}{l}23.4 \\
(4.67)\end{array}$ & $\begin{array}{l}15 \\
(3.37)\end{array}$ & $\begin{array}{l}21.5 \\
(4.49)\end{array}$ & $\begin{array}{l}23.6 \\
(6.34)\end{array}$ & $\begin{array}{l}16 \\
(1.99)\end{array}$ & $\begin{array}{l}12.8 \\
(2.27)\end{array}$ & $\begin{array}{l}15.5 \\
(3.52)\end{array}$ & - & $\begin{array}{l}18.3 \\
(1.75)\end{array}$ \\
\hline$P_{2}(\mathrm{SE})$ & $\begin{array}{c}0.306 \\
(0.16)\end{array}$ & $\begin{array}{r}0.177 \\
(0.16)\end{array}$ & $\begin{array}{r}0.250 \\
(0.19)\end{array}$ & $\begin{array}{c}0.072 \\
(0.03)\end{array}$ & $\begin{array}{r}0.110 \\
(0.06)\end{array}$ & $\begin{array}{r}0.410 \\
(0.15)\end{array}$ & $\begin{array}{c}0.216 \\
(0.11)\end{array}$ & $\begin{array}{l}- \\
-\end{array}$ & $\begin{array}{c}0.243 \\
(0.06)\end{array}$ \\
\hline
\end{tabular}

F, individuals from the snail farm; L, individuals from Lille; S, individuals from Saint-Sulpice. 
persons working separately. Paternity was established by exclusion between alleles shared by the mother, offspring and potential fathers.

\section{Statistical analyses}

To test for an equal fertilization probability of both males, we compared the observed $P_{2}$ values to a theoretical binomial distribution (Kraaijeveld-Smit et al. 2002), which means that at this stage we neglected potentially different sperm numbers transferred by each male. Sometimes clutch size was less than 20 because of failure in DNA extraction (mean $\pm \mathrm{SD}=18.1 \pm 3.59)$. Therefore, we created a binomial distribution for each sample size with the probability 0.5 of siring success for both males. We then multiplied these distributions by the corresponding number of samples of equal size and added the results to get the final distribution. A Kolmogorov-Smirnov goodness-of-fit test was used to compare the observed distribution of $P_{2}$ values and the theoretical one (Cook et al. 1997). A generalized linear model (GLM) with a binomially distributed error and a logistic link function was used to measure the influence of five independent variables on the variations of $P_{2}$ values (e.g. Evans \& Magurran 2001). Once snails were placed together, time (days) until the recipient and the first donor copulate was recorded as a potential measure of reluctance to mate and it thus could be correlated with paternity. Time (days) between first and second mating was also investigated as this variable is known to be frequently involved in patterns of paternity (Baur 1994; Evans \& Magurran 2001). As size of snails is highly correlated to the number of sperm contained in the spermatophore (Rogers \& Chase 2001), we considered the ratio of size of first donor to size of second one as an index of relative amount of sperm transmitted to the recipient (Baur 1994). Time (days) between second mating and oviposition was also considered as it is highly variable and could reflect the degree of sperm mixing within the spermatheca. The type of mating sequence treatment was the last term tested into the model and the offspring's paternity was coded as the dependent binary variable. We retained the model displaying the best Akaike information criterion (AIC) following a stepwise procedure (Venables \& Ripley 1999). The significance of each term was tested using the relative amount of deviance it explained, with $\chi^{2}$-tests (Venables \& Ripley 1999). As the residual deviance in the final model was strongly higher than the residual degrees of freedom, a 'quasi-binomial' family of error structure was used (McCullagh \& Nelder 1989). Using this family, the dispersion parameter of the GLM is not fixed to one but inferred from the data (here it was equal to 8.55) so that the observed overdispersion can be taken into account in the model. Analyses were performed using s-PLus 2000 (MathSoft Inc.) and R (Ihaka \& Gentleman 1996).

\section{Results}

Among the 78 once-mated recipients, 65 mated with a second mate and 36 laid eggs (Table 1 ). The paternity patterns were established for only 32 clutches because of the destruction of several clutches by fungal disease. DNA extraction failed for 53 out of 640 eggs and paternity was impossible to establish for eight eggs (1.36\%) because of shared alleles between putative parents. Finally, 96 parents and 579 descendants were successfully typed which revealed a mean $( \pm S E)$ proportion of offspring sired by the second mate $\left(P_{2}\right)$ of $0.24 \pm 0.06$. Multiple paternity occurred in 20 clutches $(62.5 \%)$ and among the 12 sired by one mate, nine were fertilized by the first donor and three by the second. Of the $P_{2}$ values, $82.5 \%$ are less than 0.5 , the resulting distribution appears almost unimodal with a very large variance, leading to a significant difference from the binomial distribution (Kolmogorov-Smirnov goodness-of-fit test, $k_{s}=0.48, n=32, P<0.02$; Fig. 1 ).

Results from GLM analyses revealed that $44.3 \%$ of the total deviance is explained by our model (Table 2). Ratio of the size of the sperm donors showed a sequence effect

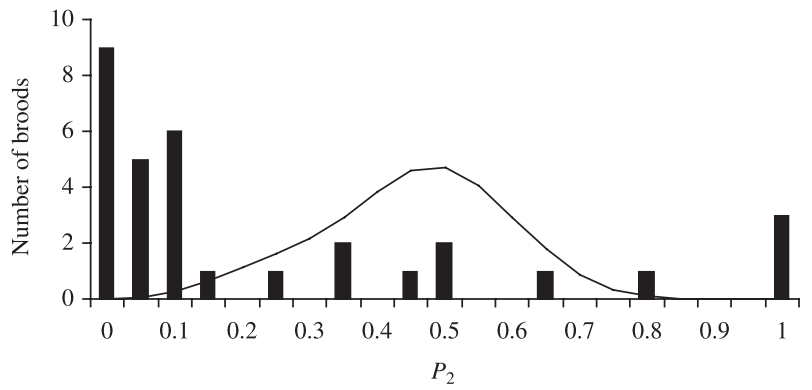

Fig. 1 Observed distribution (bars) of $P_{2}$ values (proportion of offspring sired by the second mate) and corresponding binomial distribution if both mates have an equal probability of siring success.

Table 2 Results from generalized linear modelling of $P_{2}$ against five independent variables

\begin{tabular}{lccc}
\hline Source of deviance & d.f. & $\begin{array}{c}\% \text { of total } \\
\text { deviance }\end{array}$ & $P$ \\
\hline Ratio of males size & 1 & $0.19(-)$ & 0.79 \\
Time before first mating & 1 & $13.87(+)$ & $0.02^{*}$ \\
Time before second mating & 1 & $15.38(-)$ & $0.02^{*}$ \\
Origin of first sperm donor & 2 & 0.86 & 0.85 \\
Origin of second sperm donor & 2 & 1.01 & 0.83 \\
First s.d. $\times$ second s.d. & 2 & 12.97 & 0.09 \\
\hline
\end{tabular}

s.d., sperm donor; *significant at 5\% level.

The last term entered into the model is the interaction between the populations of origin of first and second sperm donors. The sign of the regression coefficient for the continuous explanatory variables is given in brackets.

$n=32$, total deviance $=320.34$. 

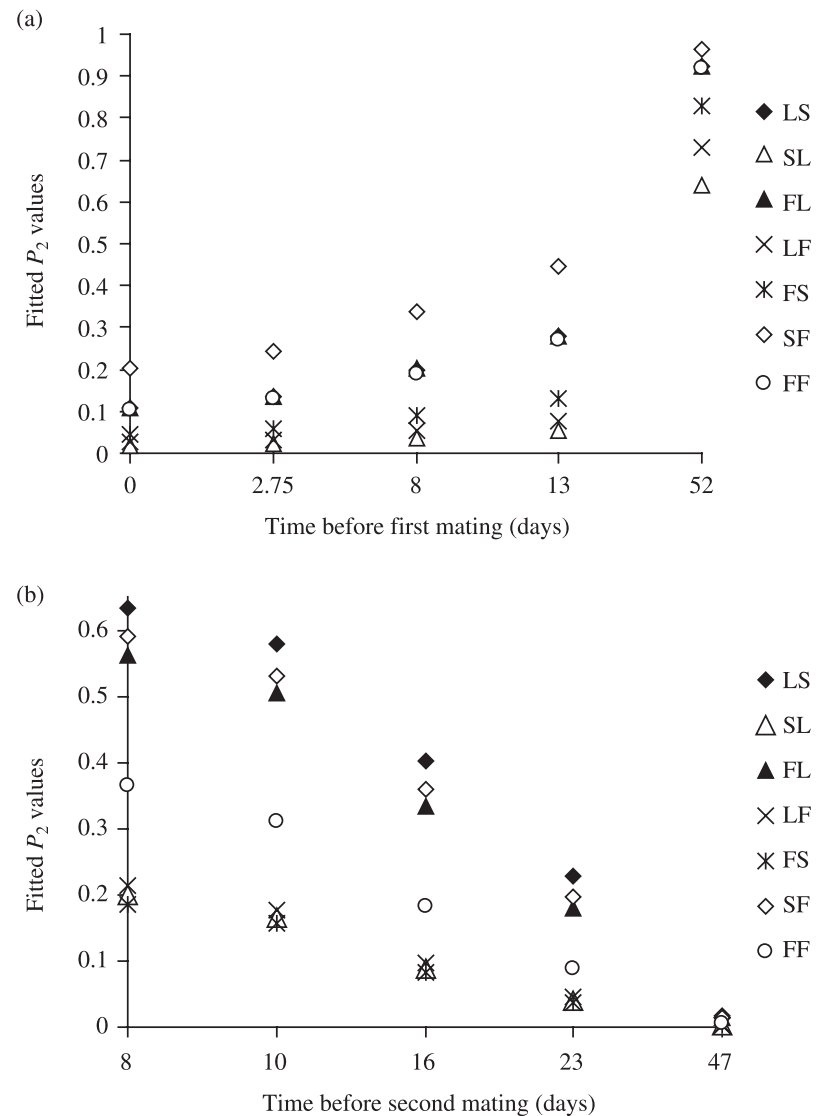

Fig. 2 GLM predictions of proportion of offspring sired by second mate $\left(P_{2}\right)$ as a function of time before first mating (a) and before second mating (b). Fitted $P_{2}$ values are given per quartile for both temporal variables and for each mating sequence [points for mating sequences FL, LS and FF overlap in (a) and those for sequences SL, LF and FS overlap in (b)]. F, individuals from the snail farm; $\mathrm{L}$, individuals from Lille; $\mathrm{S}$, individuals from Saint-Sulpice.

when entered into the model because of colinearity with other dependent variables (we got a similar result using the difference in size between mates). We retained the model with the highest amount of explained deviance and the best AIC (Venable \& Ripley 1999). Following this procedure, the time to egg laying was not retained in the final model. Most important effects come from the time before second mating, which is negatively correlated with $P_{2}$ values, and then from the time before first mating that is positively correlated with $P_{2}$. Figure 2 shows that if mating occurs after 13 days, the paternity success of the first mate decreases rapidly and similarly for the second mate, a high paternity success seems unlikely if the second mating occurs after 10 days. We also tested the effect of the ratio between the time before first mating and the time before second mating but this did not improve the fit of the model (data not shown). Time before first mating was significantly less than the time before second mating (Wilcoxon rank-sum test, $Z=3.42, P<0.001)$ but none of these variables are significantly different between mating sequences (Kruskal-Wallis $\chi_{6}^{2}=6.22, p=0.39$ and K-W $\chi_{6}^{2}=6.05, P=$ 0.41 , respectively). The effects of the origin of the first and second sperm donors are not significant. However, expressed in proportion of total deviance per degree of freedom, the interaction between these two factors accounts for $6.48 \%$ and its effect is marginally significant $(P=0.09)$. Pairwise comparisons of mating sequences involving the same populations show that the relative paternity achieved by individuals from a given population differs between pairs of mating sequences (Table 1). For example, a snail from Lille $(\mathrm{L})$ sired relatively more offspring when competing against an individual from the snail farm (F). However, in the same situation, an individual from SaintSulpice (S) has a siring success lower than the snail F. When competing together, $\mathrm{S}$ individuals do better than $\mathrm{L}$ ones, which does not correspond to their respective performances against snails $\mathrm{F}$. The mean $P_{2}$ value of sequence FF is 0.21 , which is an intermediate value close to the global mean of 0.24 (Table 1 ).

\section{Discussion}

The present study demonstrates first-mate sperm precedence in most instances in virgin Helix aspersa and thus not displaying dart-shooting behaviour. Our result differs markedly from a previous study with nonvirgin individuals, which showed no effect of mating order (Landolfa et al. 2001), paternity being mostly governed by success or failure of dart shooting. When both mates shot well or badly, $P_{2}$ was about 0.5 , but if one shot well and the other failed, the former sired significantly more progeny. However, with a similar design using nonvirgin snails, Rogers \& Chase (2002) found first-mate sperm precedence balanced by dart-shooting effectiveness. In our experiment, recurrent first-mate sperm precedence may be simply explained by the spermathecae of recipients being filled after first matings. However, singly mated snails store about 900 sperm if they did not receive any dart and about twice as many if they did (Rogers \& Chase 2001). Thus, when dealing with recipients that did not receive any dart, complete filling of their spermathecae after first mating is unlikely. Moreover, among the 12 broods sired by one father we observed nine null $P_{2}$ values. This further indicates a nonrandom advantage of first mates because possible failure in spermatophore transmission is supposed to be independent of mating order. In addition, it may be possible that dart shooting from the recipient into the second sperm donor might have influenced the amount of sperm transferred to the recipient. However, such an effect has never been documented.

In this study, dart-shooting behaviour of the sperm donors was prevented by using virgin snails. However, 
because snails were not observed continuously, it is possible that some dart-shooting events may have occurred. Indeed, virgin snails can start a courtship, display dart-shooting behaviour (without actual dart shooting), and then stop without going on until copulation (Chung 1986; Adamo \& Chase 1988). Nevertheless, this event will lead to the formation of a dart after 6 days (Tompa 1984) and this dart will be shot during the next courtship. In our experiment, it frequently took longer than 6 days for the first matings to occur: 18 out of 32 first matings and all the second matings. Thus, theoretically, some dart-shooting events may have occurred. However, it has been clearly demonstrated that the main effect of dart shooting is to increase the paternity of the shooter among the progeny of the recipient (Rogers $\&$ Chase 2002). As a result, we would expect a higher paternity for sperm donors that mated after 6 days if they had effectively shot a dart. Nonetheless, for the first sperm donors for which the comparison of both categories is possible, this is clearly not the case. Indeed, the paternity of individuals mated after 6 days was lower: 0.71 vs. 0.83 for the donors that mated before 6 days. In addition, in all of the pairs we observed during courtship before their first copulation, we never saw any darts. Also, when dart-shooting behaviour was expected, i.e. before the second mating, we observed it always from the recipient to the sperm donor. Importantly, all recipients were dissected once they had laid eggs (in order to study the anatomy of the spermatheca) and no dart was found within any snails. Overall, the occurrence of dart-shooting behaviour from a sperm donor towards a recipient was theoretically possible but our observations and results clearly demonstrate that this effect could not significantly influence the results of the present study.

Low $P_{2}$ values might also be because of the ability of helicid snails to digest allosperm (Greeff \& Michiels 1999). $H$. aspersa exhibits a sperm-digesting organ, the bursa copulatrix, hence only $0.025 \%$ of the donated sperm reach the spermatheca (Lind 1973; Rogers \& Chase 2001). Theory predicts that sperm digestion might balance benefits of multiple mating between male and female functions in simultaneous hermaphrodites (Greeff \& Michiels 1999). Recipients may display such a behaviour to reduce the fertilization success of low quality mates or to use allosperm as a source of nutrients invested in the production of eggs (Greeff \& Michiels 1999).

$P_{2}$ values were negatively correlated with the time before second mating. According to the study of Rogers \& Chase (2002), there is no effect of mating interval on sperm precedence. However, in comparison with this experiment, our measurements reflect a nonconstrained interval, i.e. snails were allowed to mate again immediately after first mating. Our result can be interpreted as a choice of the recipient that delays copulation with a second mate whose sperm may be mostly digested. Conversely, a short interval may reveal a high propensity to mate with the second partner whose sperm will be slightly or not digested hence a high $P_{2}$ value. This hypothesis is reinforced by the fact that interval between matings ranged from $8-47$ days (mean $=18$ ), but for the five $P_{2}$ values more than 0.5 , this interval was less or equal to 15 days. In addition, snails that did not store enough sperm after their first mating could try to remate quickly and those that had their spermathecae filled could be reluctant to remate (Simmons \& Siva-Jothy 1998).

We also found a positive relationship between $P_{2}$ and time before first mating, which can be interpreted by the previous explanation: the recipient is reluctant to mate with its first partner and no other snail is available, so it delays the copulation, but when it finally mates, it digests most of the received sperm. Again, this kind of hypothesis supposes that snails are able to control the digestion of allosperm and that they select their mate. According to Fearnley (1993), copulations would be mostly heterotypic, individuals from a given population being more likely to mate with partners dispersing from neighbouring populations. However, in another helicid snail, Arianta arbustorum, mating is random irrespective of size and relatedness (Baur 1992; Baur \& Baur 1997). In this species, mating can be preferentially homotypic when individuals from distant populations are experimentally mixed (Baur \& Baur 1992).

Our results strongly suggest that times before first and second copulation are reliable predictors of paternity, but whether they are under sperm donor or recipient control remains to be investigated. An individual might refuse to mate and finally accept just to digest sperm but its mating partner may also refuse to mate and only transmit a low amount of sperm; both behaviours would result in low paternity of the sperm donor. The first hypothesis seems more likely because there is no evidence that $H$. aspersa can control the amount of sperm it transmits during copulation (Rogers \& Chase 2001). An alternative view is that recipients considered as attractive by the sperm donors may accept their first mate's sperm more readily. This could be possible if, for example, there were other variables that would determine both attractiveness and fertilization rates of eggs. Time before mating most probably reflects propensity of both partners to mate with each other. Then, further experiments involving analyses of paternity of all broods produced by a group of snails allowed to choose their mates are necessary.

To explain the relationship between both temporal effects and $P_{2}$, we invoked a possible preference of the recipient towards one of the sperm donors. This preference might be based on the population of origin of mates but there is no clear pattern related to this factor. Mates from Lille outcompete sympatric ones, which is consistent with a sexual antagonistic co-evolution (Hosken et al. 2002). This result might also be explained by a cryptic choice of 
recipients towards genetically distinct mates. However, when using sperm donors from Saint-Sulpice, we got an opposite pattern with local mates siring more offspring. These different results need further investigations because the statistical power of these comparisons is limited as illustrated by the small sample size of mating sequences FL and FS.

In the beetle Callosobruchus maculates, Brown \& Eady (2001) found an advantage of sympatric males but in the dung fly Scatophaga stercoraria, Hosken et al. (2002) showed that allopatric males outcompete local ones. Several other studies have generated partly inconsistent results (reviewed in Chapman et al. 2003) and it has been suggested that a measure of population genetic differentiation could be useful for the interpretation of the observed patterns. In the case of $H$. aspersa, populations are highly structured even at a local scale (Arnaud et al. 1999, 2001). Based on the three microsatellite loci we used, average $F_{\mathrm{ST}}$ over the three populations is 0.17 and pairwise $F_{\mathrm{ST}}$ are $0.11,0.17$ and 0.28 for Farm-Lille, Farm-Saint Sulpice and Lille-Saint Sulpice, respectively [(all significant at the 5\% level, randomization test implemented in FSTAT (Goudet 2003)]. These values show that there is no relationship between geographical distance and genetic structuring between populations. We conclude that for H. aspersa populations used in this experiment, neither genetic differentiation nor geographical distances between populations strongly influence sperm precedence.

Our experiment was designed to highlight possible postcopulatory sexual selection, so the fact that recipients were not allowed to choose sperm donors may have forced them to mate just to ensure a minimal reproductive success. In other words, experimental conditions may have simulated very low density under which mate choice does not occur and the first mate has always a paternity advantage. This suggests that no postcopulatory choice of recipient based on size or population from its mate occurred. Apart from controlled allosperm digestion, such a choice may be possible providing a spermatheca subdivided in tubules where sperm from successive mates may be stored separately (Haase \& Baur 1995). In the snail A. arbustorum, some tubules can be filled while others simultaneously empty but whether there is a segregation of sperm from different mates has not yet been investigated (Haase \& Baur 1995).

Our study showed that although there is clear first-mate sperm precedence in virgin $H$. aspersa snails, time before mating is a reliable predictor of paternity. Finally, as there is a growing interest in mechanisms of postcopulatory sexual selection, hermaphroditic snails may be especially suited organisms for such studies. Reciprocal matings and sexual conflict could have led to sophisticated behaviours like allosperm digestion and dart shooting, which may balance interests of both sexual functions.

\section{Acknowledgements}

We thank J. Goudet for his advice with GLM analysis as well as X. Cucherat and G. Yannic who helped in sampling. Many thanks also to M.-A. Coutellec, J. Goudet, E. Petit, A. Ding, D. J. Hosken, F. Rousset and two anonymous reviewers who gave fruitful comments that greatly improved the manuscript. G. E. is supported by a Swiss National Science Foundation grant (no: 31-59326.99).

\section{References}

Adamo SA, Chase RA (1988) Courtship and copulation in the terrestrial snail Helix aspersa. Canadian Journal of Zoology, 66, 1446-1453.

Andersson M (1994) Sexual Selection. Princeton University Press, Princeton, New Jersey.

Arnaud J-F, Laval G (2004) Stability of genetic structure and effective population size inferred from temporal changes of microsatellite DNA polymorphisms in the land snail Helix aspersa (Gasatropoda: Helicidae). Biological Journal of the Linnean Society, 82, 89-102.

Arnaud J-F, Madec L, Bellido A, Guiller A (1999) Microspatial genetic structure in the land snail Helix aspersa (Gastropoda: Helicidae). Heredity, 83, 110-119.

Arnaud J-F, Madec L, Guiller A, Bellido A (2001) Spatial analysis of allozyme and microsatellite DNA polymorphisms in the land snail Helix aspersa (Gastropoda: Helicidae). Molecular Ecology, 10, 1563-1576.

Baminger H, Haase M (1999) Variation in spermathecal morphology and amount of sperm stored in populations of the simultaneously hermaphroditic land snail Arianta arbustorum. Journal of Zoology, 249, 165-171.

Baur B (1992) Random mating by size in the simultaneously hermaphroditic land snail Arianta arbustorum: experiments and an explanation. Animal Behaviour, 43, 511-518.

Baur B (1994) Multiple paternity and individual variation in sperm precedence in the simultaneously hermaphroditic land snail Arianta arbustorum. Behavioral Ecology and Sociobiology, 35, 413-421.

Baur B, Baur A (1992) Reduced reproductive compatibility in Arianta arbustorum (Gastropoda) from distant populations. Heredity, 69, 65-72.

Baur B, Baur A (1997) Random mating with respect to relatedness in the simultaneously hermaphroditic land snail Arianta arbustorum. Invertebrate Biology, 116, 294-298.

Birkhead TR, Pizzari T (2002) Postcopulatory sexual selection. Nature Reviews Genetics, 3, 262-273.

Brown DV, Eady PE (2001) Functional incompatibility between the fertilization systems of two allopatric populations of Callosobruchus maculatus (Coleoptera: Bruchidae). Evolution, 55, 2257-2262.

Chapman T, Arnqvist G, Bangham J, Rowe L (2003) Sexual conflict. Trends in Ecology and Evolution, 18, 41-47.

Charnov EL (1979) Simultaneous hermaphroditism and sexual selection. Proceedings of the National Academy of Sciences of the United States of America, 76, 2480-2484

Chen XF (1993) Comparison of inbreeding and outbreeding in hermaphroditic Arianta arbustorum (L.) (Land snail). Heredity, 71, 456-461.

Chung DJD (1986) Initiation of growth of the first dart in Helix aspersa Müller. Journal of Molluscan Studies, 52, 253-255. 
Cook PA, Harvey IF, Parker GA (1997) Predicting variation in sperm precedence. Philosophical Transactions of the Royal Society of London. Series B, Biological Sciences, 352, 771-780.

Duncan CJ (1975) Reproduction. In: Pulmonates (eds Fretter V, Peake J), pp. 309-365. Academic Press, London, UK.

Eberhard WG (1996) Female Control: Sexual Selection by Cryptic Female Choice. Princeton University Press, Princeton, New Jersey.

Estoup A, Largiader CR, Perrot E, Chourrout D (1996) Rapid one-tube DNA extraction for reliable PCR detection of fish polymorphic markers and transgenes. Molecular Marine Biology and Biotechnology, 5, 295-298.

Evans JP, Magurran AE (2001) Patterns of sperm precedence and predictors of paternity in the Trinidian guppy. Proceedings of the Royal Society of London. Series B, Biological Sciences, 268, 719-724.

Fearnley RH (1993) Sexual selection, dispersal and reproductive behaviour in hermaphrodite land snails, with particular reference to Helix Aspersa Müller. (Pulmonata: Gastropoda). PhD Thesis, University of Manchester, Manchester, UK.

Goudet J (2003) FSTAT version 2.9.4: A Program to Estimate and Test Population Genetics Parameters. Available from http://www.unil.ch/izea/ softwares/fstat.html.

Greeff JM, Michiels NK (1999) Sperm digestion and reciprocal sperm transfer can drive hermaphrodite sex allocation to equality. American Naturalist, 153, 421-430.

Guiller A, Arnaud J-F, Vautrin D, Solignac M (2000) Highly polymorphic microsatellite markers in the landsnail Helix aspersa (Mollusca Gastropoda). Molecular Ecology, 9, 1191-1193.

Haase M, Baur B (1995) Variation in spermathecal morphology and storage of spermatozoa in the simultaneously hermaphroditic land snail Arianta arbustorum (Gastropoda: Pulmonata: Stylommatophora). Invertebrate Reproduction and Development, 28, 33-41.

Hellriegel B, Ward PI (1998) Complex female reproductive tract morphology: its possible use in postcopulatory female choice. Journal of Theoretical Biology, 190, 179-186.

Hosken DJ, Blanckenhorn WU, Garner TWJ (2002) Heteropopulation males have a fertilization advantage during sperm competition in the yellow dung fly (Scathophaga stercoraria). Proceedings of the Royal Society of London. Series B, Biological Sciences, 269, 1701-1707.

Ihaka R, Gentleman R (1996) R: a language for data analysis and graphics. Journal of Computational and Graphical Statistics, 5, 299-314.

Koene JM, Chase R (1998) Changes in the reproductive system of the snail Helix aspersa caused by mucus from the love dart. Journal of Experimental Zoology, 201, 2313-2319.

Kraaijeveld-Smit FJL, Ward SJ, Temple-Smith PD, Paetkau D (2002) Factors influencing paternity success in Antechinus agilis: last-male sperm precedence, timing of mating and genetic compatibility. Journal of Evolutionary Biology, 15, 100-107.

Landolfa MA (2002) On the adaptive function of the love dart of Helix aspersa. Veliger, 45, 231-249.

Landolfa MA, Green DM, Chase R (2001) Dart shooting influences paternal reproductive success in the snail Helix aspersa (Pulmonata, Stylommatophora). Behavioral Ecology, 12, 773-777.

Leonard JL (1992) The 'love-dart' in helicid snails: a gift of calcium or a firm commitment? Journal of Theoretical Biology, 159, 513-521.

Lind H (1973) The functional significance of the spermatophore and the fate of spermatozoa in the genital tract of Helix pomatia (Gastropoda: Stylommatophora). Journal of Zoology, 169, 39-64.

Madec L, Guiller A (1994) Geographic variations of distal genitalia in the landsnail Helix aspersa (Mollusca, Gastropoda). Journal of Zoology, 233, 215-231.

Madec L, Coutellec-Vreto M-A, Desbuquois C (1998) Sizefecundity relationships in the land snail Helix aspersa: preliminary results on a form outside the norm. Invertebrate Reproduction and Development, 34, 83-90.

Madec L, Desbuquois C, Coutellec-Vreto M-A (2000) Phenotypic plasticity in reproductive traits: importance in the life history of Helix aspersa (Mollusca: Helicidae) in a recently colonized habitat. Biological Journal of the Linnean Society, 69, 25-39.

McCullagh P, Nelder JA (1989) Generalized Linear Models, 2nd edn. Chapman \& Hall, London.

Michiels NK (1998) Mating conflicts and sperm competition in simultaneous hermaphrodites. Sperm Competition and Sexual Selection (eds Birkhead TR, Møller AP), pp. 219-254. CA, Academic Press, San Diego.

Murray J (1964) Multiple mating and effective population size in Cepaea nemoralis. Evolution, 18, 283-291.

Parker GA (1970) Sperm competition and its evolutionary consequences in insects. Biological Reviews of the Cambridge Philosophical Society, 45, 525-567.

Parker GA, Partridge L (1998) Sexual conflict and speciation. Philosophical Transactions of the Royal Society of London. Series B, Biological Sciences, 353, 261-274.

Rice WR, Holland B (1997) The enemies within: intergenomic conflict, interlocus contest evolution (ICE), and the intraspecific Red Queen. Behavioral Ecology and Sociobiology, 41, 1-10.

Rogers DW, Chase R (2001) Dart receipt promotes sperm storage in the garden land snail Helix aspersa. Behavioral Ecology and Sociobiology, 50, 122-127.

Rogers DW, Chase R (2002) Determinants of paternity in the garden snail Helix aspersa. Behavioral Ecology and Sociobiology, 52, 289-295.

Simmons LW, Siva-Jothy MT (1998) Sperm competition in insects: mechanisms and the potential for selection. Sperm Competition and Sexual Selection (eds Birkhead TR, Møller AP), pp. 341-434. CA, Academic Press, San Diego.

Tompa AS (1984) Land snails (stylommatophora). The Mollusca, Volume 7 (eds Tompa AS, Verdonk NH, Van Den Biggelaar JAM), pp. 47-140. Academic Press, London.

Venables WN, Ripley BD (1999) Modern Applied Statistics with s-PLUS, 3rd edn. Springer-Verlag, New York.

This work was part of Guillaume Evanno's Master thesis, which was carried out under the supervision of Luc Madec. Currently PhD student at the University of Lausanne, G.E. is working on community genetics of freshwater snails. L.M. is interested in population genetics and in the evolution of life histories using land snails as model species. Jean-François Arnaud is a population geneticist who now works on the spatial structure of plant populations and on the interactions between wild beet and their cultivated relatives. 